\title{
O conhecimento científico no livro I dos Segundos Analíticos de Aristóteles
}

\author{
Lucas Angioni (UNICAMP)
}

I examine Aristotle's description of scientific knowledge in Posterior Analytics 71b 9-12 and try to understand how it relates to sophistical way of knowing an to knowledge kata sumbebekos. I claim that Aristotle's criteria for scientific knowledge includes the requirement of knowing $p$ by its apropriate cause, and that this appropriate cause is a universal (katholou) in the restricted meaning Aristotle proposes in 73b 26-27 ff., that is, an attribute convertible with the subject (an extensional feature) and predicated of the subject in itself (an intensional feature). Knowledge kata sumbebekos can occur even when the predicate of a conclusion is convertible with its subject and is proved by a convertible meson, but it is not proved by means of the relevant adequate meson.

Em Segundos Analíticos I 2, Aristóteles procura delimitar em que consiste o conhecimento científico e, nesse intento, ele parte da seguinte descrição:

"Julgamos conhecer cientificamente uma coisa qualquer, sem mais (e não do modo sofístico, por concomitância), quando julgamos reconhecer, a respeito da causa pela qual a coisa é, que ela é causa disso, e que não é possível ser de outro modo" (71b 9-12).

Não é claro se "uma coisa qualquer" (hekaston) refere-se, precisamente, a objetos (coisas consideradas em si mesmas), ou a fatos proposicionais, que envolvem a atribuição de certa propriedade a certo sujeito. Essa primeira dificuldade, no entanto, é facilmente resolvida por outros textos, principalmente por Segundos Analíticos II, 1-2: conhecemos, em sentido estrito, que certo sujeito tem certo atributo e, cientes desse fato, procuramos conhecer por que essa atribuição é o caso, e somente ao conhecer o porquê alcançamos o conhecimento científico ${ }^{1}$. Estabelecido esse ponto, podemos dizer que

\footnotetext{
${ }^{1}$ É claro que o conhecimento do porquê pressupõe e requer o conhecimento de definições, o conhecimento do sentido dos termos, etc., e Aristóteles reconhece que há outro gênero de conhecimento (71b 16-17), que é a apreensão imediata daquilo que não pode ser demonstrado (72b 18-20). Mas isso não afeta o ponto
} 
Aristóteles parece atribuir ao conhecimento científico três características ${ }^{2}$, mas não é muito claro o que cada uma delas significa. Em primeiro lugar, é claro que (i) o conhecimento científico de um objeto (isto é, de uma predicação qualquer) envolve o conhecimento da causa desse objeto. É certo, também, que (ii) o conhecimento científico envolve o conhecimento de alguma relação necessária, embora seja difícil determinar qual é, exatamente, essa relação. Finalmente, é certo que (iii) o conhecimento científico opõe-se a certo modo sofístico de conhecer os mesmos objetos de que se pode ter ciência, mas tampouco é claro em que consiste esse modo sofístico. Aristóteles parece descrevêlo pela expressão kata symbebekos (per accidens), mas tampouco é claro qual é a característica que essa expressão atribui ao conhecimento sofístico.

Neste artigo, nosso objetivo consiste em discutir essas três características atribuídas ao conhecimento científico em Segundos Analíticos 71b 9-12. Mais precisamente, procuraremos delimitar em que consiste esta última, de modo que se torne clara, também, sua articulação com as duas outras.

Aristóteles usa novamente a expressão “conhecer pelo modo sofístico” em 74a 28 9, em oposição ao conhecimento de que uma propriedade $A$ atribui-se a um sujeito $C$ per se e katholou. Por outro lado, a expressão "conhecer algo kata sumbebekos" aparece novamente em 76 4-15, quando Aristóteles afirma que devemos conhecer cientificamente cada coisa pelos seus princípios próprios. Nossa estratégia consiste em analisar comparativamente as duas passagens, no intuito de verificar se ambas as expressões, "conhecer pelo modo sofístico" e "conhecer kata sumbebekos", são usadas como equivalentes para descrever um mesmo fenômeno.

Antes disso, talvez seja útil delimitar os possíveis significados do modo sofístico. Aristóteles distingue três tipos de argumentos sofísticos ${ }^{3}$. Talvez suas distinções sejam

principal em que estamos interessados, que consiste em ressaltar que as conclusões das demonstrações relatam fatos proposicionais.

2 Porchat [2001], p. 35-6, não comenta especificamente a terceira característica, mas a assume como corolário das duas anteriores, o que não é incompatível com o que iremos propor. Barnes [1993], p. 89 é um pouco vago ao comentar a terceira característica: ele entende que haverá conhecimento kata symbebekos se não for satisfeito qualquer um dos requisitos para o conhecimento científico haplôs, mas não é claro se, entre esses requisitos, ele compreende apenas as duas características mencionadas em 71b 912, ou algo mais (como as seis propriedades das proposições demonstrativas, expostas em 71b 20-33). O fato de ele conceber como "mistake" a tentativa de encontrar uma caracterização uniforme do conhecimento kata symbebekos sugere que ele se inclina antes para esta última opção.

${ }^{3}$ Ver, nesse sentido, Dorion [1995], p. 280-1, e Shreiber [2003], p. 173-6. 
mais sutis e exaustivas, mas, para os propósitos deste artigo, basta-nos considerar os três tipos seguintes: (1) um argumento é sofístico quando ele parece concluir de modo válido, mas, de fato, não conclui, antes, comete um erro formal de inferência (cf. Tópicos 100b 25, 101a 2-4, 162b 3-5); (2) um argumento é sofístico quando, seja ele uma inferência válida ou não, ele toma como se fossem aceitas como verdadeiras premissas que, de fato, não são verdadeiras nem aceitas como verdadeiras (cf. Tópicos 100a 23-25, 101a 1-2); (3) finalmente, um argumento é sofístico quando, mesmo sendo uma inferência válida e mesmo sendo constituído de proposições verdadeiras, ele parece explicar sua conclusão de modo adequado, mas, de fato, não explica a conclusão pelo porquê adequado (171b 11-12, 162b 7-8).

Em todos os três tipos de argumentos sofísticos, a razão pela qual eles são chamados de sofísticos consiste no fato de produzirem a aparência de algo que, na verdade, não é o caso, ou, em outras palavras, no fato de parecerem ter algumas propriedades que, de fato, não têm. Assim, no primeiro caso, o argumento parece concluir de modo válido; no segundo caso, o argumento parece constituir-se de proposições verdadeiras; no terceiro, o argumento parece explicar adequadamente seu explanandum ${ }^{4}$. Comum a todos os casos é certa aparência de sabedoria que se produz pelo uso do argumento sofístico.

O conhecimento científico, para Aristóteles, requer os três requisitos envolvidos nos tipos de argumentos sofísticos acima distinguidos: um argumento conta como uma demonstração científica se ele satisfaz conjuntamente as três condições seguintes: ser um argumento válido (71b 17-19), constituir-se de proposições verdadeiras (71b 19-20, 25 27) e explicar adequadamente o objeto assumido como explanandum (cf. 71b 22-23). Mas é nesta última condição que Aristóteles concentra sua ênfase, justamente porque ela envolve as duas anteriores ${ }^{5}$. Assim, é provável que, ao definir o conhecimento científico em oposição ao modo sofístico de conhecer, Aristóteles tenha em vista sobretudo esta última condição e, conseqüentemente, o modo sofístico em contraste com o qual se desenha a noção de conhecimento científico é aquele que, embora se apresente por

\footnotetext{
${ }^{4}$ Ver Dorion [1995], p. 280-1, Shreiber [2003], p. 175.

${ }^{5}$ As duas primeiras características podem-se dar uma sem a outra, bem como sem a terceira, mas a terceira não pode dar-se sem as duas anteriores.
} 
argumentos válidos constituídos de proposições verdadeiras, produz apenas a aparência de uma explicação adequada. Vejamos se o exame do texto comprova essa hipótese.

II.

No capítulo 9 do livro I dos Segundos Analíticos, Aristóteles afirma que, para haver conhecimento científico de determinada proposição, não basta deduzi-la (por um argumento válido) de premissas verdadeiras, indemonstráveis e imediatas: é preciso deduzi-la de seus princípios próprios, ou seja, dos princípios que explicam estrita e adequadamente o fato descrito por essa proposição. Aristóteles não é muito claro sobre esse requisito mais forte, mas, de todo modo, ele parece opô-lo ao conhecimento por concomitância. Vejamos:

“(i) Conhecemos cada fato não por concomitância quando o conhecemos através da coisa em virtude da qual ele é o caso, pelos princípios dessa coisa enquanto ela é ela mesma (ii) por exemplo, o fato de possuir ângulos iguais a dois retos, conhecemo-lo pelos princípios daquilo a que se atribui por si mesmo o fato mencionado. (iii) Por conseguinte, se é por si mesmo que tal fato se atribui àquilo a que se atribui, é necessário que o mediador ${ }^{6}$ esteja na mesma família homogênea." (76a 4-9).

O exemplo de Aristóteles, na seção (ii) do trecho citado, é bem elucidativo. Ele toma como exemplo o conhecimento de que triângulos têm a soma de seus ângulos

\footnotetext{
6 Traduzimos "meson" por "mediador", em vez da expressão tradicional "termo médio". Em primeiro lugar, Aristóteles nem sempre está falando estritamente de termos: do ponto de vista linguístico, pode tratar-se de uma descrição (logos, cf. 48a 29-30, 38) e, além do mais, Aristóteles pode perfeitamente referir-se a coisas que, em relação a outras, desempenham certo papel causal. É claro que essas coisas são sempre suscetíveis de serem expressas em uma descrição, mas Aristóteles nem sempre parece interessado em tomá-las justamente enquanto elas são expressas em descrições. Em segundo lugar, o adjetivo "médio", se é que diz algo, diz algo enganador, pois parece remeter a algo que tem uma "extensão intermediária" (comparada com a extensão dos extremos de um silogismo, tal como é enganadoramente sugerido em 25b 35-36, cf. Patzig [1968], 96-99) ou a algo que ocupa uma posição intermediária na formulação do silogismo (o que é verdadeiro apenas no caso da primeira figura, cf. Patzig [1968], 101-104). Em terceiro lugar, na exposição da silogística (Primeiros Analíticos I 4-6), torna-se claro que meson é o termo que, pela sua relação respectiva com cada um dos extremos, permite, pela mera forma lógica dessas relações, que se determine como necessária uma relação entre os dois extremos (cf. 79a 33-36, bem como Primeiros Analíticos I 28, sobretudo 44b 6-10 ss.), e essa noção, que nada deve à extensão do termo ou à sua posição em uma formulação-modelo, parece-nos bem traduzida por mediador, não por médio. Finalmente, Segundos Analíticos II 2 ( $89 \mathrm{~b} 38$ ss.) concebe meson como fator que explica uma atribuição e que é suscetível de se tornar meson de um silogismo cuja conclusão expressa o fato que ele explica (embora nem todo meson de um silogismo seja um fator que explica a conclusão), e essa conexão entre explicação e análise silogística parece-nos bem traduzida por mediador, não por médio.
} 
internos igual a dois ângulos retos e, doravante, para simplificação, denominaremos esse atributo pela sigla "2R". Assim, o atributo 2R é tomado como predicado da conclusão de uma demonstração. E o sujeito que, em si mesmo (kath' hauto), recebe tal atributo 2R parece ser o triângulo (cf. 73b 33-39). Assim, pelos princípios do triângulo, enquanto triângulo, conhecemos que o triângulo tem $2 \mathrm{R}$, ou seja: pela premissa menor, que atribui ao triângulo seu princípio adequado, somada à premissa maior, que formula o atributo $2 \mathrm{R}$ como decorrente de tal princípio, concluímos que o triângulo tem $2 \mathrm{R}$.

Suponha-se que essa demonstração seja provada do modo que Eudemo atribuiu aos pitagóricos: traça-se uma paralela a um dos lados do triângulo e, pelos teoremas de equivalências entre ângulos formados por uma reta que corta duas paralelas (proposições I.28 e I.29 de Euclides), mostra-se que a soma dos ângulos internos de um triângulo resulta em 180 graus $^{7}$. Suponha-se que essa descrição que serve de mediador seja exposta pelo termo $M^{8}$. Assim, teremos o seguinte silogismo:

"2R atribui-se a $M$ ",

" $M$ atribui-se ao triângulo",

logo, "2R atribui-se ao triângulo".

Diante desse silogismo, as sentenças de Aristóteles na seção (i), em 76a 4-6, podem ser tomadas de dois modos, ambos os quais são compatíveis com essa interpretação do exemplo. De certo modo, poderíamos entender que o pronome "ekeino" em 76a 5 não designa a mesma coisa a que se refere o pronome "ekeino" em 76a $6{ }^{9}$. O primeiro "ekeino" remeteria ao mediador que, presente nas duas premissas, explica por que a conclusão é o caso (hyparchei), ao passo que o segundo "ekeino" remeteria ao sujeito da conclusão. O texto, então, diria o seguinte: "Conhecemos que $C$ é $A$ (isto é, a conclusão de uma demonstração) não por concomitância quando conhecemos a

\footnotetext{
${ }^{7}$ Não concordo com Heath [1956], p. 320, que julga que Aristóteles concebe a prova de que o triângulo tem 2R como o teorema I.32 de Euclides. Como o próprio Heath, p. 320-1, observa, Metafísica 1051a 24 evidencia que Aristóteles concebeu a prova pitagórica exposta por Eudemo, e a razão que Heath alega para preferir o teorema I.32 de Euclides parece-me totalmente inconcludente.

${ }^{8}$ Aristóteles remete precisamente a essa situação em Primeiros Analíticos I 34, 48a 33-39: o mediador $M$ não é um termo ou certo isto, mas uma descrição (logos), e supor que não haveria tal mediador, pela razão de que ele não pode ser exposto como um termo único, levaria ao paradoxo de tomar como imediato algo que pode ser demonstrado.

${ }^{9}$ Esse uso dos pronomes não é raro e há casos ainda mais extremos . Ver, em Física II 9, 200b 4, a sentença "ei de tadi, tadi", na qual as duas ocorrências de "tadi" remetem a coisas diferentes (como se Aristóteles dissesse "se $A$, então $B$ ", sendo $A$ distinto de $B$ ).
} 
proposição que $C$ é $A$ através daquilo (a saber, o termo mediador apropriado) em virtude da qual ela é o caso, pelos princípios do sujeito $C$ contido nessa proposição enquanto ele é ele mesmo".

De outro modo, a expressão "kat' ekeino" (com acusativo) em 76 a 5 seria equivalente a "kat' ekeinou" (genitivo) e remeteria ao sujeito da conclusão, cujo atributo é, precisamente, aquilo que compete à ciência demonstrar (cf. 75a 40-41), e o mesmo regime semântico valeria para "ekeinou" na linha seguinte. Teríamos, então: "Conhecemos $A$ (isto é, o predicado da conclusão de uma demonstração) não por concomitância quando conhecemos que $A$ se atribui àquilo (a saber, o sujeito $C$ ) a que [propriamente] se atribui, pelos princípios do sujeito $C$ enquanto ele é ele mesmo". A primeira leitura coaduna-se mais com a tese de que conhecemos, estritamente (no sentido de termos uma ciência acabada), proposições, não termos. Já a segunda é obtida por uma interpretação mais simples da referência dos pronomes e coaduna-se ao fato de que Aristóteles às vezes toma os termos como abreviações das proposições em que eles figuram como predicados e, em virtude disso, parece transferir aos termos certas características que se aplicam estritamente a proposições ${ }^{10}$.

Questão mais difícil e importante consiste em saber o que significa a cláusula “enquanto o sujeito é ele mesmo" (ekeinou hêi ekeino)? Obviamente, não se trata de dizer que o sujeito da conclusão é tomado, na premissa menor, como atributo tautológico de si mesmo. A cláusula "enquanto é ele mesmo" opõe-se a "enquanto é outro" e, neste contexto, esta última expressão remete ao tipo de proposição em que o sujeito é classificado sob atributo geral que, ainda que lhe pertença essencialmente, ou lhe pertença kath' hauto, não lhe é co-extensivo. Em Primeiros Analíticos I 35, 48a 35, Aristóteles afirma que o atributo $2 \mathrm{R}$ atribui-se ao triângulo "não mais por meio de outra coisa" (ouketi di' allo), pois o triângulo tem em si mesmo (kath' hauto) 2R, ao passo que $\mathrm{o}$ isósceles, que tem o atributo $2 \mathrm{R}$ por ser um triângulo, tem tal atributo "por meio de outra coisa", a saber, o triângulo. Isso não quer dizer que o triângulo é um atributo nãoessencial do isósceles, tampouco implica que a relação entre o triângulo e o atributo $2 \mathrm{R}$

\footnotetext{
${ }^{10}$ Estritamente, termos não são nem verdadeiros, nem falsos (cf. 16b 28-29, 16a 9-16), nem necessários, nem assertóricos, etc., mas Aristóteles às vezes os qualifica como verdadeiros, como contingentes (cf. 74b 31), como necessários (cf. 75a 3, 4, 8-9), justamente porque os toma enquanto predicados ou enquanto abreviações de sentenças (cf. 77b 21-22), em um contexto determinado.
} 
seja indemonstrável, ou que não exista nenhum mediador que a explique. Julgar que não há tal mediador é justamente o erro contra o qual Aristóteles se previne nesse capítulo dos Primeiros Analíticos. O ponto de Aristóteles é o seguinte: o mediador que explica por que o triângulo tem o atributo $2 \mathrm{R}$ não mais pode ser um atributo mais geral em que o triângulo fosse incluído, e que fosse, a esse título, outra coisa em comparação com o triângulo. A explicação, neste caso, não mais pode apelar para um critério de inclusão extensional. Ora, o triângulo e o atributo $2 \mathrm{R}$ são rigorosamente co-extensivos (cf. 73b 3439), e a explicação da relação necessária que vigora entre ambos há de se dar, exatamente, por um mediador que seja (i) igualmente co-extensivo com ambos os extremos e que (ii) se articule com a descrição essencial que diz o que o triângulo é em si mesmo. É isso que Aristóteles quer dizer na seção (iii) do trecho citado: "é por si mesmo [kat' hauto] que também tal coisa [o mediador] se atribui àquilo a que se atribui [o extremo menor]" e "é necessário que o mediador esteja na mesma família homogênea". Julgo que a noção de suggeneia (família homogênea), neste caso, envolve a coextensividade dos três termos da demonstração, bem com a relação não-extensional que Aristóteles demarca pela expressão kat' hauto (em sentido amplo, envolvendo os dois usos distinguidos em 73b 34-40).

Podemos retomar o texto da seção (ii), 76a 6-7. Aristóteles, assim, quer dizer que o atributo $2 \mathrm{R}$, como predicado a ser demonstrado em uma conclusão, será cientificamente conhecido (e não conhecido por concomitância) se for conhecido pelos princípios daquilo a que ele se atribui kath' hauto. Suponha-se que o atributo $2 \mathrm{R}$ atribui-se ao isósceles kath' hauto (Aristóteles parece negar isso em 48a 35-6, mas suponha-se que, em sentido mais lato da expressão "kath' hauto", possamos afirmar que o isósceles tem 2R kath' hauto). Ora, neste caso, os princípios do isósceles, que explicam por que ele tem a propriedade $2 \mathrm{R}$, não se podem esgotar na noção de triângulo, pois não é suficiente, para demonstrar $2 \mathrm{R}$ do isósceles, subsumir o isósceles na classe dos triângulos. É preciso, ainda, acrescentar, como princípio apropriado da demonstração, o princípio pelo qual se explica por que o triângulo tem o atributo 2R. Sem esse princípio, ou seja, tão somente pela subsunção do isósceles à classe dos triângulos, não temos conhecimento científico da proposição “todo isósceles tem 2R". Se pretendermos explicar esta proposição apenas pelo fato de que o isósceles é triângulo, sem considerar as razões que fazem o triângulo 
ter a propriedade $2 \mathrm{R}$, teremos dela um conhecimento apenas por um concomitante: isto é, por um atributo mais geral sob o qual se classifica o sujeito da proposição a ser explicada, mas que, a rigor, não explica apropriadamente o explanandum. Pela subsunção do isósceles a um atributo geral (sumbebekos) ${ }^{11}$, ainda não alcançamos o "porquê último", pois ainda podemos e devemos perguntar por que o triângulo tem o atributo $2 \mathrm{R}$, e, conseqüentemente, ainda não atingimos a causa primeira que explica adequadamente o explanandum. Se esse conhecimento por um atributo geral (sumbebekos) for apresentado ou alardeado como se fosse conhecimento científico, teremos, justamente, o modo sofístico a que alude Aristóteles em 71b 9-10: teremos um silogismo válido, constituído de proposições verdadeiras, mas no qual a conclusão, ao contrário do que se pretende, não é explicada de modo apropriado pelo seu princípio primeiro.

III.

Em Segundos Analíticos I 5, Aristóteles alude ao modo sofístico pelo qual se poderia conhecer que triângulos têm a soma de seus ângulos internos igual a dois retos. Esse modo sofístico aparece em oposição ao conhecimento de que o triângulo tem $2 \mathrm{R}$ per se e katholou. O capítulo em seu todo busca caracterizar casos em que, apesar de julgarmos ter alcançado uma demonstração universal e per se, não a alcançamos. Assim, antes de mais nada, precisamos entender o que Aristóteles entende por demonstração universal e per se e, para tanto, devemos considerar o que Aristóteles diz a esse respeito no trecho que encerra o capítulo 4.

Aristóteles, em 73b 26-39, delimita os critérios para um uso bem específico do termo "universal" (katholou): não se trata da noção trivial de atributo que "se predica de mais de uma coisa" (Interpretação 17 $7^{\mathrm{a}} 39-40$ ), mas trata-se de um atributo que é coextensivo com o sujeito a que se atribui e que se lhe atribui per se. Para caracterizar o requisito da co-extensividade entre sujeito e atributo katholou, Aristóteles diz o seguinte: “o universal se dá precisamente quando se atesta a respeito de qualquer caso que se tome, e primeiramente" $\left(73^{\mathrm{a}} 32-33\right)$.

\footnotetext{
${ }^{11} \mathrm{O}$ termo symbebekos em vários contextos tem o sentido de mero atributo ou, mais precisamente, de predicado que não é próprio ao sujeito a que se atribui. Ver adiante os dois exemplos da Metafísica: o atributo homem em relação a Cálias (981a 18-20) e esfera em relação à esfera de bronze (1033a 29-31).
} 
Não é difícil entender o que Aristóteles quer dizer com essas duas características: (i) o universal é um atributo que se mostra verdadeiro a respeito de qualquer caso particular contido no sujeito de que se predica, e essa característica é comum a qualquer predicado universal latu sensu e corresponde ao que Aristóteles demarcou com a expressão "kata pantos" em $73^{\mathrm{a}} 28-34^{12}$. Como ela não é suficiente para marcar em que consiste o universal no sentido estrito pretendido no texto, Aristóteles acrescenta a segunda característica: (ii) o universal é um atributo que tem as mesmas condições de aplicação que o termo que lhe serve como sujeito, como Aristóteles mais bem explica em 74 38 - 74b 4 (texto ao qual voltaremos) e logo na seqüência: "ter dois ângulos retos não é universal para a figura (...); já um isósceles qualquer tem ângulos iguais a dois ângulos retos, mas não primeiramente, pois é o triângulo que é anterior" (73b 33-39).

Os exemplos são mais elucidativos que a formulação conceitual que Aristóteles propõe para as características do atributo katholou, mas não há controvérsia a respeito do que Aristóteles quer dizer. O núcleo de seu argumento consiste em dizer que ser triângulo é, conjuntamente, condição suficiente e condição necessária para ter $2 \mathrm{R}$, o que não se dá para a figura (que é apenas condição necessária), nem para o isósceles (que é apenas condição suficiente). Em suma, é katholou, neste sentido estrito, o atributo que se aplica exatamente ao mesmo domínio de objetos a que se aplica o sujeito a que se atribui. Mas, como veremos, a esse critério extensional, Aristóteles acrescenta um não-extensional: o predicado katholou se atribui a seu sujeito em si mesmo.

Aristóteles, então, retoma a caracterização do atributo katholou: "o [sujeito] que, em qualquer caso que se tome, primeiramente mostra-se dotado de dois ângulos retos (ou outro atributo qualquer), é o [sujeito] primeiro a que [esse atributo, 2R] se atribui como universal" (73b 39- $\left.74^{\mathrm{a}} 1\right)$.

No entanto, ao prosseguir seu argumento, Aristóteles propõe noções bem diversas, embora dependentes da noção de atributo katholou: a noção de demonstração katholou, e a noção de uma demonstração que envolve atribuições per se:

“a demonstração é universal a respeito deste item primeiro (toutou), em si mesmo, mas, de certo modo, não é kath' hauto a respeito dos demais itens, tampouco é universal a respeito do isósceles, mas sim "sobre mais casos"” (74 $1-3)$.

\footnotetext{
12 Em suma, “Todo $A$ é $B$ ” quer dizer que, para todo $x$, se $x$ é $A$, então $x$ é $B$.
} 
A tradução que adotamos requer comentário cuidadoso. Primeiramente, devemos examinar a que se refere o pronome "toutou" em $74^{\mathrm{a}} 1$. Seria correto dizer que uma demonstração tem por objeto, precisamente, a relação predicativa expressa na conclusão. Demonstra-se, por exemplo, que o triângulo têm o atributo 2R. Muitas vezes, Aristóteles dá a entender que o objeto da demonstração é o atributo relatado na conclusão, mas isso pode ser entendido como modo abreviado de dizer que se demonstra, precisamente, que o atributo pertence a um dado sujeito. No entanto, nada impede que, neste contexto, o pronome "toutou" refira-se ao sujeito da conclusão demonstrativa. Está já implícito na sentença de Aristóteles que o atributo envolvido na demonstração, e que de certo modo é o objeto da demonstração (cf. 75a 40-41, 76b 6-11), é o atributo 2R. Trata-se de saber a que sujeito esse atributo pertence per se e katholou (cf. 73b 39- 74a 3). E a proposição na qual se atribui a esse sujeito, per se, o predicado $2 \mathrm{R}$ como katholou será a conclusão de uma demonstração katholou, na qual o demonstrandum se explica por uma atribuição per se. Assim, o pronome "toutou" refere-se ao triângulo e apresenta-se em oposição ao pronome "tôn allôn", que se reporta aos casos específicos de triângulo, como o isósceles. O contraste que Aristóteles quer ressaltar é o seguinte:

1) a demonstração de que o atributo $2 \mathrm{R}$ (como termo maior) atribui-se ao sujeito triângulo (como termo menor) é uma demonstração katholou.

1') já a demonstração de que o atributo $2 \mathrm{R}$ (como termo maior) atribui-se ao sujeito isósceles (como termo menor) não é uma demonstração katholou ("tampouco é universal a respeito do isósceles", $74^{\mathrm{a}}$ 2-3), mas uma demonstração na qual o atributo a ser explicado aplica-se (pela mesma razão) também a mais casos (“epi pleion”), como o eqüilátero e o escaleno.

Por outro lado, esse contraste parece ser tido como equivalente ao seguinte:

2) a demonstração de que o atributo $2 \mathrm{R}$ (como termo maior) atribui-se ao sujeito triângulo (como termo menor) é uma demonstração per se, isto é, uma demonstração na qual a atribuição de $2 \mathrm{R}$ ao triângulo foi explicada tomando-se, na premissa menor, o triângulo em si mesmo.

2') já a demonstração de que o atributo $2 \mathrm{R}$ (como termo maior) atribui-se ao sujeito isósceles (como termo menor) é uma demonstração, mas não é uma demonstração per se katholou $\left(74^{\mathrm{a}}\right.$ 2), nem uma demonstração sem mais (haplôs, 76a 14), isto é, não é 
uma demonstração na qual a atribuição de $2 \mathrm{R}$ ao isósceles fosse explicada tomando-se o isósceles em si mesmo, pois, na premissa menor, o isósceles é justamente tomado como outra coisa, a saber, como triângulo.

Assim, Aristóteles parece querer dizer que a demonstração:

“2R atribui-se a todo $B$ ”

" $B$ atribui-se a todo triângulo",

"2R atribui-se a todo triângulo",

é uma demonstração katholou porque (i) os termos extremos são co-extensivos, de modo que (ii) o mediador também é forçosamente, co-extensivo com ambos os extremos;

e é uma demonstração per se porque (iii) o termo mediador é um atributo que se predica do termo menor em si mesmo. Falta determinar em qual sentido de "em si mesmo".

Por contraste, Aristóteles parece querer dizer que a demonstração:

"2R atribui-se a todo $B$ "

" $B$ atribui-se a todo isósceles",

"2R atribui-se a todo isósceles",

não é uma demonstração katholou porque (i) os termos extremos não são co-extensivos, de modo que (ii) o mediador tampouco é co-extensivo com o termo menor;

não é uma demonstração per se porque (iii) o termo mediador não é um atributo que se predica do termo menor em si mesmo. Falta determinar em qual sentido de "em si mesmo".

Essa análise gera algumas expectativas. Talvez a expressão “ou kath’ hauto” em $74^{\mathrm{a}} 2$ seja equivalente a "kath' heteron" e a "kata sumbebekos", simplesmente no sentido de que (i) a relação predicativa em pauta não envolve termos co-extensivos, mas, antes, envolve um predicado que se atribui a mais casos, de modo que (ii) o predicado em questão não pode ser estritamente correlato à definição do sujeito. Como Aristóteles usa a expressão “ou kath' hauto" para se referir à relação predicativa que se estabelece na premissa menor de uma demonstração, podemos dizer que, no segundo silogismo acima exemplificado, a atribuição do predicado $2 \mathrm{R}$ ao isósceles não foi explicada pela definição do isósceles, nem, portanto, pela sua causa primeira ${ }^{13}$. Se estivermos corretos, essa

\footnotetext{
13 Sobre a noção de causa primeira e sua relação com o porquê último, ver Física 194b 19-20 e 198a 16-18.
} 
análise permite entender em que consiste o modo sofístico pelo qual se pode conhecer que o triângulo e o isósceles tem $2 \mathrm{R}$.

IV.

Consideremos a prova, à qual Aristóteles alude em 74a 13-16:

(a') "as retas que formam ângulos iguais ao cortarem uma terceira não se encontram"; "duas perpendiculares formam ângulos iguais ao cortarem uma terceira"; logo, "duas perpendiculares não se encontram”.

Note-se que a premissa menor do silogismo (a') pode ser deduzida de premissas anteriores: "ângulos retos são ângulos iguais"; "duas perpendiculares formam ângulos retos ao cortarem uma terceira"; logo, "duas perpendiculares formam ângulos iguais ao cortarem uma terceira".

Assim, poderíamos dizer que:

(b') "as retas que formam ângulos retos ao cortarem uma terceira não se encontram"; "as perpendiculares formam ângulos retos ao cortarem uma terceira"; logo, "as perpendiculares não se encontram".

Para Aristóteles, a explicação adequada do fato de duas perpendiculares a uma terceira reta não se encontrarem é o fato de que os ângulos que ambas formam com a terceira são iguais de qualquer modo que seja (hopôsoun isai, 74a 16, para qualquer valor que venham a assumir), mas não o fato de que os ângulos que ambas formam com a terceira são iguais de um modo determinado, a saber, enquanto são ângulos retos (hôdi isai, 74a 15-6).

Do mesmo modo, se considerarmos o procedimento pelo qual se prova o atributo $2 \mathrm{R}$, teremos algo semelhante. Tomemos um isósceles, e tracemos uma linha paralela a um de seus lados. Evidencia-se, assim, que os três ângulos internos do triângulo somam $180^{\circ}$. Suponha-se que tenhamos algo como $75^{\circ}+30^{\circ}+75^{\circ}=180^{\circ}$. Mas, se tomarmos um escaleno, mudarão os valores de cada um dos fatores no lado esquerdo da equação. Teremos algo como $60^{\circ}+65^{\circ}+55^{\circ}=180^{\circ}$. Ora, os ângulos internos do isósceles serão iguais a $180^{\circ}(2 \mathrm{R})$ de um modo determinado, a saber, conforme a equação $75^{\circ}+30^{\circ}+75^{\circ}$ 
$=180^{\circ}$, ao passo que os ângulos internos do escaleno serão iguais a $180^{\circ}$ (2R) de outro modo determinado, a saber, conforme a equação $60^{\circ}+65^{\circ}+55^{\circ}=180^{\circ}$. Em ambos os casos, porém, a equação se verifica e, por isso, atribui-se verdadeiramente aos dois triângulos a propriedade $2 \mathrm{R}$. Mas a causa apropriada pela qual cada um dos triângulos tem o atributo $2 \mathrm{R}$ não é a igualdade determinada em cada equação particular, mas sim o fato de que são triângulos, isto é, figuras delimitadas por três linhas retas, de tal modo que, para qualquer valor de cada ângulo interno, a soma dos mesmos será sempre 2R, como se evidencia traçando-se uma linha paralela a um dos lados.

Existem três tipos de triângulo: o equiilátero, para o qual, na equação " $a+b+c=$ $180^{\circ}$ ", são iguais entre si os valores de $a, b$ e $c$; o isósceles, para o qual, na equação " $a+$ $b+c=180^{\circ}$ ", são iguais entre si dois valores, entre os valores de $a, b$ e $c$; e o escaleno, para o qual, na equação " $a+b+c=180^{\circ}$ ”, os valores de $a, b$ e $c$ são diferentes entre si. No entanto, essa especificidade de cada tipo de triângulo é irrelevante para a prova do atributo 2R. Alguém, ao provar que o atributo 2R é verdadeiro a respeito do isósceles, poderia tomar como causa o fato de que, na equação " $a+b+c=180^{\circ}$ ", os valores de duas variáveis são idênticos. Ao proceder desse modo, estaríamos no mesmo caso daquele que julga que duas linhas perpendiculares a uma terceira não se encontram porque formam com a terceira ângulos retos, e não porque formam ângulos que são iguais entre si de qualquer modo.

Parece ser esse o tipo de situação que Aristóteles descreve na passagem de Segundos Analíticos I-5 em que menciona o "modo sofístico" de conhecer. Citaremos o trecho em seu todo e marcaremos suas sub-divisões com letras, para facilitar o comentário subseqüente:

"Por isso, (i) se alguém provar a respeito de cada triângulo (ou com uma única demonstração, ou com diversas) que cada um possui dois ângulos retos - separadamente, o eqüilátero, o escaleno e o isósceles - (ii) ainda não saberá que o triângulo tem ângulos iguais a dois retos (a não ser pelo modo sofístico), (iii) nem que isso se atribui como universal [katholou] ao triângulo, mesmo se não houver outro triângulo além destes. (iv) Pois, neste caso, ele não saberia enquanto é triângulo, nem que todo triângulo, a não ser por contagem; mas, pela forma, não saberia que todo triângulo, mesmo se não existisse nenhum que ele não conhecesse" $\left(74^{\mathrm{a}} 25-32\right)$. 
Para a interpretação dessa passagem, devemos enfrentar duas questões. A primeira consiste em saber qual é a prova a que Aristóteles se refere na seção (i) deste trecho. A segunda questão consiste em saber o que Aristóteles pretende ilustrar com essa prova. Ora, em todo capítulo 5 do livro I dos Segundos Analíticos, Aristóteles pretende ilustrar o caso em que, em uma demonstração, a conclusão não apresenta um atributo que seja katholou em relação ao sujeito, embora assim se tenha pretendido. No entanto, "um predicado não-universal em relação ao sujeito da conclusão" é uma expressão ambígua. Poderíamos julgar que Aristóteles, com essa prova, pretende introduzir o caso em que, entre o sujeito e o predicado de uma conclusão demonstrativa, não há co-extensão, pois o predicado aplica-se a mais casos, como no caso do predicado $2 \mathrm{R}$, que não é co-extensivo com o isósceles (cf. 73b 38-39). É possível que Aristóteles esteja interessado também neste caso, mas é preciso notar que a noção estrita de predicado katholou, neste contexto, não se define apenas extensionalmente, mas pela conjunção entre a co-extensividade com o sujeito e a propriedade intensional de atribuir-se ao sujeito enquanto tal. Assim, mesmo para certos predicados que são co-extensivos com o sujeito a que se atribuem, é possível que, em uma demonstração, não se tenha provado que eles se atribuem ao sujeito em si mesmo ou enquanto tal, isto é, em virtude de suas características essenciais. Talvez Aristóteles esteja interessado justamente em ilustrar casos em que, ainda que o predicado da conclusão seja co-extensivo com o sujeito, não se demonstrou que ele se atribui ao sujeito em virtude de suas características essenciais.

Tentemos, então, reconstituir a prova a que Aristóteles alude. Para facilitar a análise, suporemos que a prova em questão recebe uma formulação silogística. Nessa perspectiva, uma coisa é certa: o extremo maior, isto é, o predicado da conclusão, no silogismo em pauta, é o atributo 2R. Quanto ao extremo menor, o sujeito da conclusão, Aristóteles considera, inicialmente, que o sujeito é o conjunto dos três triângulos (“escaleno, equiilátero e isósceles"), de modo que se tem uma única demonstração, ou é, a cada vez, um dos três tipos de triângulo, separadamente, de modo que teremos três demonstrações, uma para cada espécie de triângulo. O problema é que, como veremos, Aristóteles passa imperceptivelmente desses silogismos, em que o sujeito da conclusão é um dos tipos de triângulo (ou todos eles), para outro silogismo, no qual o sujeito da conclusão é o triângulo. 
A dificuldade maior concentra-se em decidir qual seria o termo mediador que Aristóteles tem em vista nesta passagem. Considere-se a equação " $a+b+c=180^{\circ}$ ”, na qual as letras representam os ângulos internos de um triângulo. Teemos, no lado esquerdo da equação, o termo mediador do silogismo em pauta, e a mencionada equação contará como premissa maior do mesmo. Por exemplo:

" $30^{\circ}+75^{\circ}+75^{\circ}=2 \mathrm{R}\left(180^{\circ}\right)$ "; "este isósceles tem os ângulos internos no valor de $30^{\circ}$, $75^{\circ}$ e $75^{\circ}$ "; logo, "este isósceles tem 2R".

Poderia parecer que Aristóteles quer dizer que, em casos como este, "ainda não se sabe que o triângulo tem $2 \mathrm{R}$, a não ser pelo modo sofístico". Mas o argumento pode (e deve) ser tomado de outro modo. Sem delongas e sem aviso prévio, Aristóteles passa a considerar a relação entre o triângulo e o atributo 2R. Assim, à luz das seções anteriores deste artigo, tentemos averiguar se o modo sofístico de conhecer que o triângulo tem $2 \mathrm{R}$ é um conhecimento kata sumbebekos. Talvez Aristóteles remeta ao caso em que o conhecimento de que o triângulo tem $2 \mathrm{R}$ é obtido pelas premissas de que "isósceles tem 2R" e "isósceles é um triângulo". O triângulo é atributo (sumbebekos) do isósceles e, por isso mesmo, parece ter, de certo modo, a mesma propriedade que o isósceles. Aristóteles freqüentemente usa a expressão "kata sumbebekos" nesse mesmo sentido. Assim, um médico cura homem, kata sumbebekos, porque o médico cura Cálias e Cálias é um homem (ou seja, ser homem é atributo, sumbebekos, de Cálias, cf. Metafísica 981a 1820), e "um produtor produz a esfera kata sumbebekos" porque ele produz esta esfera de bronze, e esta esfera de bronze é uma esfera (cf. Metafísica 1033a 29-31). Em boa silogística aristotélica, o máximo a que se poderia chegar, por esse caminho, seria a conclusão (em Darapti) de que algum triângulo tem 2R. Se alguém pretende, por essa via, ter alcançado a conclusão universal de que todo triângulo tem $2 \mathrm{R}$, não terá senão produzido um sofisma, neste caso, um argumento flagrantemente não-válido.

No entanto, talvez a questão de Aristóteles não consista em simplesmente acusar o modo sofístico de propor uma falácia na terceira figura silogística. Talvez o modo sofístico de conhecer que todo triângulo tem $2 \mathrm{R}$ não seja caracterizado por um erro formal de inferência. Suponha-se que a prova do atributo $2 \mathrm{R}$ seja repetida, com as devidas adaptações, para os demais tipos de triângulo, isto é, o escaleno e o eqüilátero (é a isso que Aristóteles se refere em 74a 25-7). Suponha-se que se saiba devidamente que 
esses três tipos de triângulo exaurem todas as espécies possíveis de triângulo (74a 29$30)^{14}$. Neste caso, sabemos que "todos os triângulos têm 2R". No entanto, ainda assim não sabemos que o triângulo, enquanto triângulo, tem $2 \mathrm{R}$, e apenas por contagem sabemos que o atributo $2 \mathrm{R}$ atribui-se a todo triângulo, pois não o sabemos em virtude da forma essencial comum a todo triângulo.

Assim, em 74a 25-32, Aristóteles parece ter em vista a seguinte situação:

"O eqüilátero, o isósceles e o escaleno têm (cada um respectivamente) 2R";

“Todo triângulo é ou equiilátero, ou isósceles, ou escaleno";

Logo, "Todo triângulo tem 2R"15.

Construída essa prova, que é um argumento válido e constitui-se de proposições verdadeiras, teríamos, ainda, conhecimento da conclusão pelo modo sofístico, que equivale a conhecê-la por meio de um atributo irrelevante (um sumbebekos) para a explicação adequada. Ainda que a verdade da premissa menor seja totalmente garantida (como Aristóteles enfatiza na cláusula "mesmo se não existir nenhum outro triângulo além destes"), não se saberia que o atributo $2 \mathrm{R}$ atribui-se ao triângulo universalmente (no sentido estrito de katholou $^{16}$ ), isto é, não se saberia que todo triângulo tem $2 \mathrm{R}$ enquanto triângulo e em virtude da forma essencial do triângulo (kat' eidos). Obviamente, ao dizer que não se saberia que $2 \mathrm{R}$ atribui-se como katholou ao triângulo, Aristóteles não quer dizer que não se saberia que triângulo e $2 \mathrm{R}$ são noções co-extensivas. Aristóteles é bem enfático a respeito disso: ainda que a co-extensão esteja totalmente garantida ("ainda que não exista nenhum outro tipo de triângulo além dos três"), não se tem conhecimento científico, se essa co-extensão é obtida por mera contagem, sem referência à forma essencial do triângulo enquanto triângulo. Como Aristóteles afirma em 76a 4-7, conhecemos cientificamente que o triângulo tem $2 \mathrm{R}$ quando o conhecemos "pelos princípios do triângulo enquanto triângulo", e ter três espécies parece não ser um

\footnotetext{
${ }^{14}$ Note-se que a equação " $a+b+c=180^{\circ}$ " permite ver claramente a razão pela qual existem somente três espécies de triângulo: ou os três valores, para $a, b$ e $c$, são iguais (eqüilátero), ou dois deles são iguais (isósceles), ou todos são desiguais entre si (escaleno).

${ }^{15}$ Ross [1949], p. 526, assim interpretou o modo sofístico, acertadamente, a meu ver.

${ }^{16}$ Os códices variam entre trigônon (acusativo) e trigônou (genitivo), mas todos apresentam katholou, e não vejo a razão pela qual Ross [1949], p. 526, corrige katholou para kath' holou. Basta ler trigônou, com o manuscrito $n$.
} 
princípio relevante, ou melhor, parece não ser a propriedade essencial relevante, pela qual se evidencia que o triângulo tem $2 \mathrm{R}$.

O capítulo 5 do livro I dos Segundos Analíticos inicia-se com o propósito de atestar casos em que o predicado de uma conclusão demonstrativa não se atribui como universal ao sujeito, ao contrário do que pretendem os que propuseram a demonstração. Esse tipo de erro (apatê, 74a 7) ocorre quando, por algumas das razões listadas em 74a 710, toma-se como se fosse co-extensivo com o predicado um sujeito de menor extensão. No entanto, em 74a 25-32, Aristóteles parece considerar outra variedade desse mesmo erro, a que depende das propriedades intensionais dos sujeitos a que se atribui o predicado katholou. Assim, mesmo em casos nos quais está assegurada a co-extensão entre sujeito e predicado, pode-se, no contexto da demonstração, tomar o predicado como katholou sem se levar em consideração que ele se atribui ao sujeito em si mesmo ou enquanto ele é ele mesmo.

V.

Em relação à premissa maior da prova que reconstituímos, a saber, a proposição “o equiilátero, o isósceles e o escaleno têm (cada um respectivamente) 2R", poderíamos determinar em que condições Aristóteles diria que ela é conhecida apenas kata sumbebekos e pelo modo sofístico.

Há duas possibilidades (para simplificar, tomaremos apenas o isósceles): ou a demonstração dessa proposição se dá do modo que já exemplificamos acima, pela equivalência dos ângulos formados por uma reta que corta duas linhas paralelas (e isto sempre aplica-se aos dois lados do triângulo, em relação a uma reta paralela ao lado restante):

(a) " $a+b+c=2 \mathrm{R}\left(180^{\circ}\right)$ "; "isósceles tem os ângulos internos no valor de $a, b$ e $c$ "; logo, “isósceles tem 2R".

Ou a demonstração assume como mediador simplesmente o termo "triângulo": (b) "todo triângulo tem 2R", "todo isósceles é triângulo", logo, "todo isósceles tem 2R". Em momento algum Aristóteles descreve a demonstração (a) como conhecimento sofístico ou conhecimento kata sumbebekos. Na verdade, para reconstituí-la, na seção III 
deste artigo, atribuímos valores determinados $\left(30^{\circ}+75^{\circ}+75^{\circ}\right)$ aos ângulos internos do isósceles apenas para garantir o paralelo com a demonstração de que duas perpendiculares a uma terceira não se encontram. A prova de que os ângulos internos de um isósceles somam $180^{\circ}$ não exige que se conheça determinadamente o valor de cada um desses ângulos: basta que se saiba o teorema da equivalência dos ângulos formados por uma linha que corta duas paralelas, e que se saiba o que significa um ângulo de $180^{\circ}$. $\mathrm{Na}$ verdade, em tal prova, o isósceles é, inevitavelmente, tomado apenas enquanto triângulo: basta considerá-lo como figura plana limitada por três linhas, pois basta traçar a paralela a um dos lados para verificar o atributo 2R: pelo teorema da equivalência entre ângulos "externos" e "internos" formados por uma reta que corta duas paralelas, vê-se que os três ângulos internos de um triângulo perfazem, juntos, um ângulo de $180^{\circ}$, qualquer que seja o valor de cada um dos três ângulos ${ }^{17}$.

Por outro lado, a demonstração (b), em si mesma, apenas subsume o isósceles à classe que é co-extensiva com o atributo $2 \mathrm{R}$, e sua premissa maior ainda requer explicação.

Se alguém toma a demonstração (b) sem ter conhecimento da demonstração anterior pela qual se conclui a premissa maior, terá um conhecimento pelo modo sofístico: estará de posse de um silogismo válido, com três proposições verdadeiras; no entanto, na medida em que seu conhecimento da premissa maior "todo triângulo tem $2 \mathrm{R}$ " não considera a causa que realmente explica por que o atributo em questão é verdadeiro a respeito de todo triângulo e, portanto, não se articula ao conhecimento da forma do triângulo, ele a tem como indemonstrada, e, embora a saiba verdadeira, não sabe por que ela é verdadeira. Consequientemente, ele não detém a explicação apropriada do fato relatado na conclusão do silogismo (b), ou seja, não sabe qual é a causa apropriada pela qual se explica que o isósceles (bem como os demais tipos de triângulo) tem 2R.

VI.

\footnotetext{
${ }^{17}$ Esta seria a demonstração simpliciter de que todo triângulo tem 2R. Observe-se que, para construí-la, deve-se expor o triângulo em um desenho singular, e o triângulo assim exposto será um triângulo singular, de um dos três tipos (pois não há um triângulo universal à parte dos três tipos de triângulo, cf. 85b 18-22). No entanto, o fato de que o triângulo exposto na prova é (por exemplo) um isósceles não implica que ele seja tomado enquanto isósceles, pois ele é tomado enquanto triângulo.
} 
O que Aristóteles diz no capítulo 24 do livro I dos Segundos Analíticos confirma a interpretação que estamos a propor. Em Segundos Analíticos I-24, Aristóteles discute se a “demonstração universal" é melhor que a "demonstração particular". Essa nomenclatura, presente já na formulação do problema (cf. 85a 13-15), é bem enganadora: o leitor desatento facilmente suporá que "universal" e "particular" (assim como "afirmativa", katêgorikê, e "negativa" sterêtikê) são termos que pertencem ao quadro conceitual da silogística (24a 16-20, 28a 8-9, 29b 2), de modo que Aristóteles estaria a discutir se, por exemplo, demonstrações em Barbara (cuja conclusão é uma afirmativa universal) são superiores a demonstrações em Darii (cuja conclusão é uma afirmativa particular). No entanto, não há espaço, na concepção aristotélica de ciência, para demonstrações em Darii, nem para outras cuja conclusão fosse uma proposição particular, pois proposições particulares estão excluídas do domínio daquilo que pode ser cientificamente conhecido (cf. Metafísica Z-15, 1039b 27-1040a 2), isto é, daquilo que pode ser explicado por relações causais adequadas que não podem ser de outro modo. Além disso, ao prosseguir a discussão, os exemplos de Aristóteles deixam bem claro que ele está interessado no mesmo contraste que o preocupou no capítulo 5 do mesmo livro: trata-se, pois, de confrontar a demonstração "universal" que conclui que todo triângulo tem $2 \mathrm{R}$ e a demonstração "parcial" que conclui que todo isósceles tem 2R (cf. 85a 26-27, b 4-13). Obviamente, ambas as demonstrações são em Barbara, e a segunda é chamada de "parcial" (kata meros) justamente porque o termo-sujeito da conclusão é uma parte, isto é, um tipo específico contido na noção de triângulo em seu todo (cf. 74a 9-12), à qual, como termo-sujeito da demonstração universal, a propriedade $2 \mathrm{R}$ atribui-se como universal no sentido estrito.

A discussão de Aristóteles em Segundos Analíticos I-24 é bem pormenorizada e não preciso examinar todos seus detalhes. Aristóteles propõe duas razões que acusariam a inferioridade da demonstração universal, as quais, sob a devida análise, mostram, ao contrário, que a universal é melhor que a parcial. Em seguida, essa mesma tese, que a universal é melhor que a parcial, é provada por mais sete ou oito argumentos, muitos dos quais apelam para razões que são irrelevantes para o desenvolvimento da teoria da 
demonstração na qual Aristóteles está empenhado ${ }^{18}$. Consideraremos apenas a primeira objeção inicial contra a superioridade da demonstração universal, bem como dois argumentos subseqüentes (85b 23-27, 85b 27-86a 3), que acabam por pressupor ou retomar a primeira objeção ${ }^{19}$.

No primeiro argumento (85a 20-31, b 4-15), o critério proposto para medir a excelência das demonstrações universais e parciais explicita-se na seguinte sentença: "quando conhecemos cada coisa em si mesma, conhecemo-la mais do que quando a conhecemos por outra" (85a 23-24).

Tomemos a estrutura de um Barbara: se "Todo $B$ é $A$ " (premissa maior) e "Todo $C$ é $B$ ” (premissa menor), então “Todo $C$ é $A$ ” (conclusão). O que Aristóteles quer dizer é que há mais conhecimento (ou conhecimento mais apropriado) quando o termo mediador $B$, atribuído a $C$ na menor, não é outra coisa em relação a $C$, mas é a própria coisa $C$, tomada sob uma descrição essencial adequada. O problema consiste em saber qual tipo de demonstração (a parcial ou a universal) assume como termo médio a própria coisa e, portanto, fornece um conhecimento de cada coisa em si mesma. Na exposição inicial do argumento, Aristóteles supõe que esse critério é satisfeito pela demonstração parcial, não pela demonstração universal. Essa suposição é apenas uma concessão em vista do argumento: supõe-se que a demonstração universal prova um atributo de certo sujeito não porque esse sujeito é tomado em si mesmo, mas na medida em que esse sujeito é tomado (na premissa menor da demonstração) como sendo outra coisa, isto é, na medida em que se predica desse sujeito um atributo universal em sentido lato: prova-se que o isósceles

\footnotetext{
${ }^{18}$ Eis o sentido de "logika" em 86a 22: argumentos que apelam para teses que são mais gerais do que o assunto em pauta e que não são relevantes para o desenvolvimento específico do assunto em pauta.

${ }^{19}$ A segunda objeção contra a superioridade da demonstração universal liga-se também de modo claro ao capítulo 5 do livro I dos Segundos Analíticos. O trecho 85a 37-b 1 retoma o mesmo exemplo de 74a 17-25: a prova de que "o proporcional é alternado" (isto é, que, se $A$ está para $B$ como $C$ está para $D$, então $A$ está para $C$ como $B$ está para $D$, etc.). $O$ argumento de 85a 31-b 3 parece fornecer uma razão a mais para a "falsa catolicidade" de demonstrações: quando há uma noção comum (por exemplo, triângulo) a vários tipos especificamente distintos (eqüilátero, isósceles, escaleno), seja essa noção anônima ou não, pode-se relutar em tomá-la como sujeito a que propriamente se atribui um predicado katholou no sentido estrito, dado que, aparentemente, essa noção comum poderia introduzir a falsa concepção de que haveria algo distinto (cf. 85b 19), à parte dos tipos específicos, como sujeito próprio do katholou. Essa noção comum seria assim reduzida a mero termo que não corresponderia a nada real (corresponderia a um mê on, cf. 85a 36 ), e as demonstrações teriam por sujeito $C$ antes os tipos específicos. Em 85b 18-22, Aristóteles responde que não há nenhuma necessidade de tomar o termo comum a que se atribui o predicado katholou em sentido estrito como uma nova entidade, que existisse à parte dos tipos específicos pelos quais unicamente esse termo pode ser exposto.
} 
tem 2R porque é triângulo (cf. 85a 27-28). Já a demonstração parcial supostamente provaria um atributo de certo sujeito na medida em que esse sujeito é ele mesmo e não outra coisa (cf. 85a 28). No entanto, essa exposição inicial não se sustenta: Aristóteles prontamente mostra, em 85b 4-15, que é o inverso que ocorre (e não admira que ele não tenha dado nenhum exemplo de demonstração parcial em que o sujeito $C$ fosse tomado em si mesmo, porque tal exemplo é impossível e contraditório). $\mathrm{O}$ atributo $2 \mathrm{R}$ predica-se do triângulo enquanto triângulo e, para conhecer cientificamente essa proposição, devese demonstrá-la por um mediador que não é outra coisa senão uma descrição essencial do triângulo e co-extensiva com ele. Pode-se provar que o atributo $2 \mathrm{R}$ predica-se do isósceles, mas, nessa prova, deveremos assumir como mediador uma descrição que não assume o isósceles enquanto isósceles (isto é, uma descrição essencial que lhe fosse coextensiva), mas enquanto triângulo (isto é, uma descrição que é, no sentido aqui relevante, outra coisa em relação ao isósceles). Como Aristóteles afirma:

"se ter ângulos iguais a dois ângulos retos pertence ao isósceles não enquanto isósceles, mas enquanto triângulo, aquele que sabe que o isósceles tem tal atributo porque é isósceles sabe menos conforme à própria coisa do que quem o sabe porque é triângulo" $(85 b 5-7)^{20}$.

Tomemos agora o argumento desenvolvido em 85b 27-86a 3. O critério para comparar a demonstração universal com a parcial consiste na tese de que conhecemos algo, propriamente, quando o reportamos à sua causa primeira, que torna desnecessário prosseguir com a pergunta "por quê",21. Como Aristóteles afirma:

“conhecemos algo, no mais alto grau, nas seguintes condições: quando não mais se dá que $B$ é o caso porque $D$ é o caso" (85b 37-38).

Escolhemos os termos $B$ e $D$ para facilitar a compreensão do que Aristóteles quer dizer. Suponha-se a estrutura silogística de primeira figura, já exposta antes: um atributo $A$ atribui-se a $C$ devido ao mediador $B$. Mas o próprio mediador $B$ poderá ser atribuído a $C$ em virtude de outro termo $D$. No entanto, quando a conexão predicativa entre $B$ e $C$ é imediata (isto é, não admite ser explicada por um termo anterior), o termo $B$ é

\footnotetext{
${ }^{20}$ Assim como quem julga que duas linhas perpendiculares a uma terceira não se encontram porque formam um ângulo reto com a terceira sabe menos do que quem julga que elas não se encontram porque formam com a terceira ângulos respectivamente iguais.

${ }^{21}$ Aristóteles parece retomar o mesmo tipo de argumento em Segundo Analíticos II 17.
} 
precisamente o "porquê último" e a causa primeira do fato reportado na proposição "Todo $C$ é $A$ ". Assim, quando encontramos uma predicação que explica outras atribuições e não mais precisa nem pode ser explicada por predicações anteriores, encontramos a causa primeira e o porquê, e é nestas condições que encontramos uma predicação universal. Diz Aristóteles:

“quando reconhecemos que os ângulos externos são iguais a quatro retos porque é um isósceles, ainda resta saber por que o isósceles tem tais ângulos - porque é triângulo, e este, porque é uma figura retilínea. Se isto não mais é o caso devido a outra coisa, é em tal circunstância que mais conhecemos. E, nessa circunstância, conhecemos universalmente (kai katholou de tote). Portanto, a demonstração universal é melhor" (85b 38-86a 2).

Aristóteles quer dizer que, quando a conexão predicativa entre $B$ e $C$ é imediata, (i) temos uma predicação katholou, na qual $B$ é uma descrição essencial de $C$ e convertível com $C$, e, em virtude disso, (ii) temos uma demonstração universal de que a propriedade $A$ atribui-se a $C$ devido a $B$.

Entende-se de modo mais claro o que Aristóteles queria dizer no parágrafo precedente, em 85b 23-27, que agora examinaremos. Se uma demonstração é um silogismo válido com proposições verdadeiras e que realmente explica o porquê e apresenta a causa adequada do fato relatado na conclusão; e se esta última condição (explicar o porquê pela causa adequada) é satisfeita quando o termo mediador é uma descrição essencial convertível com o termo menor (quando é um atributo katholou no sentido estrito), então, a demonstração se dá quando o mediador é um atributo katholou. $\mathrm{O}$ argumento exposto em 85b 24-26 pode ser interpretado de duas maneiras, conforme leia-se em 85b 25 hautôi ou autôi. Com a lição autôi, parece-me mais sensato tomar autôi como antecedente posposto do pronome relativo hô $i$ em $85 \mathrm{~b} 24$, de modo que tal termo, qualificado pela oração relativa, refere-se ao sujeito $C$ da estrutura silogística de primeira figura, sendo o ti o termo $A$ (o predicado da conclusão), e touto auto, qualificado como aition, remete ao termo mediador $B$ e retoma katholou de $85 \mathrm{~b} 24$ (que está fora do parêntese na edição de Ross). Assim, a sentença diria o seguinte: isto mesmo, a saber, o katholou, como mediador $B$, é a causa para essa coisa, $C$, à qual se atribui, em si mesma, o predicado A. Mas, com a lição hautôi, o antecedente do pronome relativo hôi em 85b 
24 seria touto auto, referindo-se ao sujeito $C$, e hautôi remeteria ao mesmo termo $C$. Aristóteles quer dizer que, quando a atribuição do predicado $A$ a $C$ é kath' hauto em sentido estrito (cf. 74a 1-2), o mediador que explica tal atribuição é uma descrição essencial de $C$ e convertível com $C$, de tal modo que se poderia dizer que o próprio termo $C$, nesta medida, é causa para si mesmo, isto é, é a causa pela qual ele mesmo tem o atributo $A$.

VII.

Assim, mostramos que a demonstração científica, em sentido estrito, exige um mediador que seja katholou em sentido estrito: enquanto katholou, o mediador é uma descrição essencial do termo menor $C$ e co-extensiva com os demais termos envolvidos na demonstração. Em contraste com essa rede de conceitos, tornou-se também claro em que consiste o conhecimento pelo modo sofístico, que em 71b 9-12 é descrito também pela expressão "kata sumbebekos".

Podemos acrescentar que a noção de causa envolvida na definição do conhecimento científico em 71b 9-12 não remete a qualquer causa que seja suficiente para explicar, de algum modo, o explanandum (e que, portanto, possa desempenhar a função de mediador em um silogismo válido com proposições verdadeiras). Trata-se da causa adequada, que tem como requisitos (i) ser co-extensiva com o explanandum (que é relatado na conclusão da demonstração) e (ii) ser um atributo que, na premissa menor, predica-se do sujeito em si mesmo, enquanto ele é tomado em suas características essenciais. De outro modo, pode-se dizer que a causa adequada deve ser um predicado katholou (embora nem todo predicado katholou seja causa).

Quanto à noção de necessidade envolvida na definição do conhecimento científico em 71b 9-12, já se observou que não se trata da mera noção de necessidade lógica ${ }^{22}$, que caracteriza qualquer silogismo válido, e há dificuldades em se conceber tal necessidade em termos de existência eterna do objeto a respeito do qual se tem conhecimento. Podemos sugerir (e prometer como assunto de outro artigo, que virá a complementar o que estamos a propor neste) que a necessidade em questão é de outra natureza (ainda que

${ }^{22}$ Ver Porchat [2001], p. 38-43, Barnes [1993], p. 91-2. 
alguns objetos de conhecimento científico existam eternamente, etc.). O que é necessário é o que não pode ser de outro modo. Mas o que não pode ser de outro modo, no contexto da relação causal da qual há conhecimento científico? Certamente, dada a causa, segue-se o efeito, e isso não pode ser de outro modo (ou seja, não pode ocorrer que, dada a causa, o efeito não se siga dela). No entanto, neste contexto, Aristóteles quer dizer algo mais forte: dado o efeito, ele só pode ser explicado cientificamente, sem mais, pela causa adequada, que é também primeira, e é isso que não pode ser de outro modo: a causa adequada é condição suficiente e condição sine qua non para explicar o explanandum ${ }^{23}$.

\section{REFERÊNCIAS BIBLIOGRÁFICAS}

- BARNES, J. [1993]. Posterior Analytics, 2a . ed., Oxford: Clarendon Press.

- BEKKER, I. [1961]. Aristotelis Opera, (editio altera Olof Gigon), Berlin: Walter De Gruyter.

- DORION, Louis-A. [1995]. Aristote: les réfutations sophistiques, Paris: Vrin/ Laval.

- HEATH, Thomas. [1956]. Euclid: the thirteen books of the Elements, Vol. 1 (Books I and II), New York: Dover Publications.

- PATZIG, G. [1968]. Aristotle's theory of the syllogism, trad. J. Barnes, Dordrecht: Reidell.

- PORCHAT PEREIRA, Oswaldo. [2001]. Ciência e Dialética em Aristóteles, S. Paulo: Edunesp.

- ROSS, W. D. [1949]. Aristoteles: Analytica Priora et Posteriora, Oxford: Clarendon Press.

- SCHREIBER, S. G. [2003]. Aristotle on false reasoning, Albany: SUNY Press.

\footnotetext{
${ }^{23}$ Várias propostas interpretativas contidas neste artigo foram discutidas nos seminários sobre os Segundos Analíticos do Projeto Temático FAPESP "A filosofia de Aristóteles", de agosto de 2006 a maio de 2007. Agradeço a Marco Zingano, Roberto Bolzani, Vivianne Moreira e Cristiano Rezende pelas elucidativas discussões sobre o conhecimento pela causa adequada e o conhecimento kata sumbebekos.
} 